\title{
Brachytherapy: A New Weapon Against Coronary Restenosis
}

Rob Silver

Thomas Jefferson University

Follow this and additional works at: https://jdc.jefferson.edu/tmf

Part of the Cardiology Commons

Let us know how access to this document benefits you

\section{Recommended Citation}

Silver, Rob (2001) "Brachytherapy: A New Weapon Against Coronary Restenosis," The Medicine Forum: Vol. 3 , Article 8.

DOI: https://doi.org/10.29046/TMF.003.003

Available at: https://jdc.jefferson.edu/tmf/vol3/iss1/8

This Article is brought to you for free and open access by the Jefferson Digital Commons. The Jefferson Digital Commons is a service of Thomas Jefferson University's Center for Teaching and Learning (CTL). The Commons is a showcase for Jefferson books and journals, peer-reviewed scholarly publications, unique historical collections from the University archives, and teaching tools. The Jefferson Digital Commons allows researchers and interested readers anywhere in the world to learn about and keep up to date with Jefferson scholarship. This article has been accepted for inclusion in The Medicine Forum by an authorized administrator of the Jefferson Digital Commons. For more information, please contact: JeffersonDigitalCommons@jefferson.edu. 


\section{Brachytherapy: A New Weapon Against Coronary Restenosis}

Robert Silver, MD, Resident, Department of Internal Medicine 1999-2002

Since its introduction in the late 1970's, coronary angioplasty has become a common procedure for treating coronary atherosclerotic disease. It offers significant improvement in symptoms of coronary artery disease through a less invasive procedure than coronary artery bypass grafting (CABG). Each year, over 500,000 percutaneous transluminal coronary angioplasty (PTCA) procedures are performed in North America alone. In larger epicardial vessels that are 3 millimeters or greater in diameter, a metal stent can be placed during angioplasty to reduce the incidence of restenosis. In fact, stents are now deployed in approximately 80 percent of PTCA procedures. The success rate of PTCA in achieving significant dilatation of stenotic lesions and relief of symptoms of angina approaches 90 percent. However, restenosis occurs in approximately 30 to 40 percent of patients within six months of PTCA alone, and in 20 to 30 percent of patients who undergo stent placement. Repeat PTCA can be performed following restenosis, but the risk of further episodes of restenosis increases as well.

The mechanism behind coronary artery restenosis is believed to be a combination of factors mitigated by responses to vessel injury caused by PTCA, including remodeling of the damaged artery and thickening of the artery intima ${ }^{1}$. Stenting does reduce the risk of restenosis by 30 to 50 percent over balloon angioplasty alone, by preventing the constrictive remodeling of the artery. However, stenting actually results in an increase in neointimal proliferation, a mechanism that leads to in-stent restenosis. Peak incidence of restenosis occurs within three months after stenting and is rare after twelve months.

A number of interventions to reduce the incidence of restenosis have been studied over the past twenty years. Pharmacological agents such as ACE-inhibitors, calcium channel blockers, lipid-lowering agents, steroids, low-molecular-weight heparin, fish oil, and antioxidants have all been ineffective in significantly inhibiting restenosis. Once instent restenosis develops, no pharmacological or mechanical therapy (including repeat PTCA, debulking with Rotablator, or restenting) can effectively reduce recurrent restenosis.

However, one promising new tool developed over the last several years against in-stent restenosis is brachytherapy, the delivery of intracoronary radiotherapy. Cardiologists at
Thomas Jefferson University have been participating in brachytherapy patient trials since 1997, and FDA approval of two devices for brachytherapy was granted in November 2000. According to data from the triple-blinded STents and Radiation Therapy (START) trial (which includes cardiologists from Thomas Jefferson University), in-stent restenosis is reduced from 41 to 14 percent with the Novoste Beta-Cath ${ }^{\mathrm{TM}}$ intravascular brachytherapy system vs. balloon angioplasty alone ${ }^{2}$. A number of previously published randomized trials including SCRIPPS, WRIST, PREVENT and Gamma-One have also demonstrated 24$37 \%$ reduction in restenosis in patients treated with other systems of brachytherapy over placebo ${ }^{3}$.

The brachytherapy procedure at Thomas Jefferson University begins with selection of an appropriate candidate. Patients who require the placement of a new mechanical stent during PTCA are excluded, as studies have shown a significant incidence of late thrombosis when brachytherapy is performed on freshly implanted stents. Patients are also excluded if they are considered high risk for the prolonged administration of antiplatelet agents required after brachytherapy, or have received prior radiation therapy. Certain patients with tortuous coronary arteries may also be excluded due to mechanical difficulties in passing the somewhat bulky radiation catheter through the vessel.

Immediately after the stenosed artery is successfully treated by angioplasty, a closed-end radiotherapy catheter is inserted over a coronary guide wire to the appropriate site. A train of radioactive seeds of Strontium 90/Yttrium 90 is then administered by a Radiation Oncologist using a handheld hydraulic device. The radiation is administered for the desired amount of time (usually 3 to 4 minutes) depending on the diameter of the lesion, and then withdrawn to an afterloader device. All of the radiation remains in the catheter during the procedure, protecting both the patient and the physician.

According to Michael P. Savage, MD, Director of the Cardiac Catheterization Laboratory at Thomas Jefferson University Hospital, the Novoste Beta-Cath ${ }^{\mathrm{TM}}$ system used at Thomas Jefferson offers several advantages over the other FDA-approved device, the Cordis Checkmate ${ }^{\mathrm{TM}}$ system. The Beta-Cath ${ }^{\mathrm{TM}}$ system uses beta-radiation rather than gammaradiation. Beta-radiation presents a lower tissue penetra- 
tion than gamma-radiation, so medical personnel do not have to leave the catheterization lab during the administration of radiation. The amount of time that beta-radiation dwells in the vessel is also much more reasonable, from 3 to 4 minutes rather than 15 to 20 minutes with gammaradiation. These factors make the use of brachytherapy a seamless addition to the PTCA procedure for in-stent restenosis.

The most significant complication of brachytherapy is the potential development of coronary thrombosis with the first month after the procedure. The Gamma-One Trial, published in January 2001, revealed a 5.3 percent incidence of late thrombosis in a group of patients treated with gammaradiation brachytherapy versus 0.8 percent incidence in placebo group $(\mathrm{p} \text { value }=0.07)^{4}$. This resulted in a higher incidence of myocardial infarction due to thrombosis in the study group over the placebo group. One possible explanation is that the radiation that prevents neointimal hyperplasia also prevents normal endothelium from growing in the vessel, leading to thrombosis. For this reason, patients at Thomas Jefferson University Hospital received clopidogrel for six months after brachytherapy. Trials studying the effect of prolonged antiplatelet therapy on late thrombosis after brachytherapy are ongoing.

At the present time, brachytherapy is limited to preventing further episodes of in-stent stenosis. If coronary radiation could be used after balloon angioplasty or initial stenting to prevent restenosis, brachytherapy would have an even larger role. Investigators at Thomas Jefferson University participated in the Beta-Cath ${ }^{\text {TM }}$ System Trial to study brachytherapy in this capacity. However, unpublished results from trial failed to show a significant decrease in the rate of restenosis with brachytherapy after PTCA than from PTCA alone. Randomized, large-scale studies are ongoing to examine an expanded role for brachytherapy. For now, the lack of conclusive data and the higher incidence of late thrombosis when treating de novo lesions make brachytherapy unsuitable for the prevention of restenosis.

In the near future, physicians and patients can expect even more weapons in the growing arsenal against restenosis. Sonotherapy, in which a therapeutic ultrasound wave is delivered after angioplasty, promises to inhibit intimal prolifera- tion without exposing the patient to any ionizing radiation. In fact, the Department of Cardiology at Thomas Jefferson University is likely to begin patient trials of sonotherapy soon. Another possible breakthrough is the use of drug-coated stents to inhibit the development of restenosis. Stents have been coated with antithrombic agents such as heparin and phosphenylcholine, as well as immunosuppressive agents such as rapamycin and paclitaxel. Both approaches hope to inhibit the neointimal proliferation that can occur in noncoated stents. However, until these new technologies come into mainstream practice, brachytherapy is likely to offer the most effective method of preventing coronary restenosis after stenting.

\section{References}

1. Bittl JA. Advances in coronary angioplasty. $\mathrm{N}$ Engl J Med 1996;335:1290-302.

2. Prepublication data from STents and Radiation Therapy (START) trial, Novoste Corporation.

3. Sheppard R, Eisenberg MJ. Intracoronary radiotherapy for restenosis. N Engl J Med 2001;344:295-7.

4. Leon MB, Teirstein PS, Moses JW, et al. Localized intracoronary gamma-radiation therapy to inhibit the recurrence of restenosis after stenting. $\mathrm{N}$ Engl J Med 2001;344:250-6. 